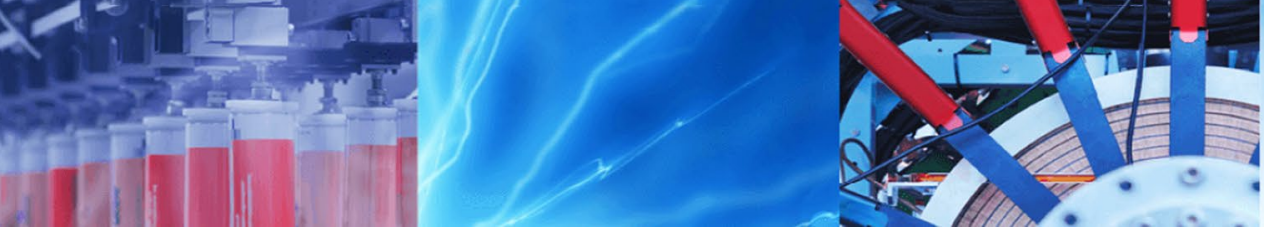

Short Communication

\title{
Investigation on MWCNT-epoxy films at high CPVC for conductive electrodes coating
}

\author{
Paolo Gronchi ${ }^{1}$ - Simone Visigalli ${ }^{2}$ (D) . Cristina Diaz Jiménez ${ }^{3}$ - Gonzalo Garcia Fuentes ${ }^{3}$. Giuseppe Di Florio ${ }^{4,5}$. \\ Andrea Turolla ${ }^{2} \cdot$ Roberto Canziani ${ }^{2}$
}

(c) Springer Nature Switzerland AG 2019

\begin{abstract}
Incineration units for sewage sludge disposal require a $40 \%$ minimum of dry solid content to obtain an ignitable material for energy recovery. Electro-dewatering (EDW) process could be useful to accelerate and improve the removal of adsorbed/interstitial water from sludge, but this application must be as cheap as possible and, further, the use of noble metals as electrodes to avoid corrosion is not appropriate. With these constraints, the use of an organic conductive coating could be suitable to protect low carbon steel electrodes. In this work, we investigated the chemical, electrical and mechanical characteristics of coatings obtained with epoxy resin/multi-walled carbon nanotube (MWCNT) composites, with the aim to design a protective film. The filler/resin ratio is the main parameter to be considered because at high ratio the electrical conductivity increases and, on the reverse, the physical and mechanical performances worsen. Specimens with different concentrations of carbonaceous filler have been produced and their characteristics have been discussed in relation to the critical pigment volume concentration (CPVC) and to the percolation limit.
\end{abstract}

Keywords MWCNT · Epoxy resin · Conductive coatings · Electro-dewatering

\section{Introduction}

Conductive organic coatings applied to protect the metal electrodes against corrosion have advantages, like low production cost, low energy consumption and easy application, if compared to bare stainless steels or metal-coated steels [1]. The above performances are of special interest for industrial applications and sustainability. In the electro-dewatering (EDW) systems for sewage sludge [2], one critical aspect is represented by the anode durability, due to the high current densities, the oxygen evolution, and the strong acid $\mathrm{pH}$ at the anode side [3]. In the EDW process, indeed, the applied voltages are up to several tens of volts, with current densities up to $100 \mathrm{~mA} / \mathrm{cm}^{2}$. The production of protons at the anode may cause a significant $\mathrm{pH}$ decrease in the sludge cake, resulting in an acidic environment, and the oxidation of the anodic material may reduce the process efficiency. Therefore, anodes made of conventional stainless and nickel steel have sufficient strength, but they easily encounter corrosion, and may cause secondary pollution in the sludge cake or in the filtrate due to eluted metal ions [1]. Hard metal coatings are normally applied to prevent corrosion, but the cost of the technologies (PVD or electrodeposition) and the low productivity (batch process) exceed the process profitability. On the other side, conductive polymers alone, e.g. polyaniline (PANI) or polyvinylpyrrolidone (PVP), suitable for protective films, have limited thermal and electrical stability, low durability and relatively poor mechanical properties,

$\triangle$ Simone Visigalli, simone.visigalli@polimi.it | ${ }^{1}$ Department of Chemistry, Materials and Chemical Engineering, Politecnico di Milano, Piazza Leonardo da Vinci 32, 20133 Milan, Italy. ${ }^{2}$ Department of Civil and Environmental Engineering - Environmental Section, Politecnico di Milano, Piazza Leonardo da Vinci 32, 20133 Milan, Italy. ${ }^{3}$ AIN-Asociación de la Industria Navarra, Ctra. Pamplona 1, 31191, Cordovilla, Pamplona, Spain. ${ }^{4}$ X2 Solutions Srl, Via XXI Luglio 20, 41037 Mirandola, Italy. ${ }^{5}$ Present Address: Department of Biotechnology, Chemistry and Pharmacy, University of Siena, via A. Moro 2, 53100 Siena, Italy. 
which are all mandatory characteristics for their application on electrodes. Due to their excellent mechanical and chemical properties, titanium coated with mixed metal oxides (MMOs) are today considered as the best candidates for the EDW process [4]. However, the high cost of MMO anodes [5] may increase the investment costs of equipment for the implementation of the EDW process at full scale. Nowadays, conductive nanomaterials mixed to organic polymers represent a possible solution for two main reasons: these coatings allow good mechanical and physical performances and their application process is easy and inexpensive also on complex surfaces $[6,7]$. Significant efforts are consequently carried out to produce new conductive polymer composites, particularly by addition of conductive carbonaceous fillers, like CNT, graphene or graphite, to non-conductive polymer matrices $[8,9]$. However, the carbon fillers have both low electrical percolation threshold (EPT) [10-12] and a very low critical pigment volume concentration (CPVC), which, in many cases, do not meet the specifications required for conductive performance. In a previous work we described the durability of ceramic thin films on stainless steel electrodes tested in a lab-scale apparatus [3]. In this work, we report the results of the investigation on the mechanical and electrical properties of composite organic coatings, composed of MWCNTs dispersed in epoxy resin, at concentrations higher than the percolation limit value and CPVC. The $w / w$ percentage of the prepared composite materials is up to $50 \%$ MWCNT, a value never reported in literature for similar applications. Durability tests in operating conditions similar to those described for ceramic coatings are under investigation.

\section{Materials and methods}

\subsection{Epoxy resin}

The epoxy resin (Gelson s.r.l., MS65213, Lainate, Milano, Italy) was based on Bisphenol-A 2-(Chloromethyl)oxirane, with mono[(C12-14-alkyloxy) methyl] derivatives (9-20 wt\%) and propylene carbonate (1-5 wt\%). The viscosity of the yellowish polymer is $1000-1200 \mathrm{MPa}$ s and the specific weight is $1.130 \mathrm{~g} / \mathrm{ml}$ (Gelson s.r.l. product datasheet). An alkaline hardener (Gelson s.r.l., MS65520, Lainate, Milano, Italy), based on polyoxypropylendiamine, was used. It contains m-phenylenebis(methylamine) (10-25 wt\%) and benzyl alcohol (5-9 wt\%). The viscosity is $120 \mathrm{mPa} \cdot \mathrm{s}$ and the specific weight $1.020 \mathrm{~g} / \mathrm{ml}$ (Gelson s.r.l. product datasheet); the non-volatile part was experimentally verified to be about $95 \mathrm{wt} \%$.

\subsection{Solvent and dispersant}

Hexane (99.8\%) and N,N-dimethylformamide (99.8\%) (Sigma-Aldrich) were used as received. A polycarboxylate comb-polymer was used as dispersant. It was synthesized with about $70 \%$ of free carboxylic functionalities on the backbone and the remaining part substituted by methoxyterminated PEO 1000. The molecular weight was approximately $30,000 \mathrm{~g} / \mathrm{mol}$.

\subsection{MWCNTs}

Multi-Walled Carbon Nanotubes (MWCNTs) were provided by the Nanotubes Section of the CMIC Dept. of the Politecnico di Milano (Milano, Italy). The CNT purity was higher than $93 \%$ and the residual part $(<7 \%)$ was constituted by inorganic material (Fe and $\mathrm{Al}$ ) and oxygen. The bulk density was $26-36 \mathrm{~kg} / \mathrm{m}^{3}$ (CMIC product datasheet).

\subsection{Preparation of the formulations}

Five dispersions at 4, 6, 8, 20, $50 \mathrm{wt} \%$ of MWCNT were prepared. As an example, the formulation of the sample at MWCNTs concentration of $20 \mathrm{wt} \%$ was: $220 \mathrm{~g}$ of $\mathrm{N}$, N-dimethylformamide, $5.9 \mathrm{~g}$ of MWCNTs, $0.5 \mathrm{~g}$ of dispersant T588 - a polycarboxylate polymer prepared with $30 \%$ of carboxylic group esterified with MPEG (Italcementi S.p.A. product datasheet) —and $20.0 \mathrm{~g}$ of epoxy resin.

The preparation of each formulation of the solutions comprehended several steps (Fig. 1). The method followed the indications reported by Chakraborty et al. [13]. At first, MWCNT powder was gradually added to the solution of N, $\mathrm{N}$-dimethylformamide and dispersant. The mix was then left under probe sonication (home-made instrument), at $28 \mathrm{kHz}$ for $2 \mathrm{~h}$, in an ice-cooled bath to keep the temperature constant at $25^{\circ} \mathrm{C}$.

After the sonication step, the MWCNT-solvent dispersion was mechanically stirred for $24 \mathrm{~h}$ at $500 \mathrm{rpm}$. When the mechanical stirrer was switched off, a high-speed disperser was activated for $5 \mathrm{~min}$ at $9000 \mathrm{rpm}$, the epoxy resin was added and the stirring step was repeated for further $24 \mathrm{~h}$ at $750 \mathrm{rpm}$. Then, the hardener was added to the solution at a ratio of 1:2 with respect to the epoxy resin and the dispersion was mechanically stirred for further $24 \mathrm{~h}$.

\subsection{Substrate preparation}

The MWCNT-epoxy composite coating was applied on carbon steel plates with standard dimensions of $60 \times 60 \times 1 \mathrm{~mm}$. The elemental composition of steel was: C 0.05 wt $\%$, Si 0.01 wt $\%$, Mn 0.23 wt $\%$, Cr 0.03 wt $\%$, 


\section{Addition CNT}

CNT added during sonication to $\mathrm{N}, \mathrm{N}$-Dimethylformamide and T588
Sonication I-II

$1 \mathrm{~h}$ sonication followed by 1 h sonication in ice bath @ $\mathrm{T}=25^{\circ} \mathrm{C}$
Stirring

$24 \mathrm{~h}$ mechanical stirring @ 500 rpm

\section{Turbomixing}

5 minutes turbomixing @ 9000 rpm followed by $24 \mathrm{~h}$ mechanical stirring @750 rpm
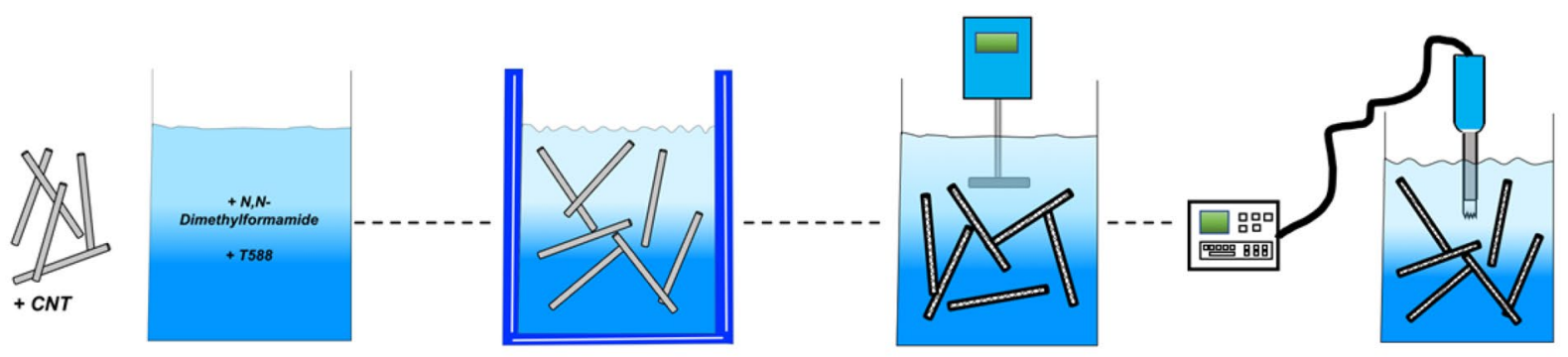

Addition Resin

Add resin and leave $24 \mathrm{~h}$ in mechanical stirring @ 750 rpm
Turbomixing

5 minutes turbomixing @ 9000 rpm
Stirring

$24 \mathrm{~h}$ mechanical stirring @ 750 rpm

\section{Deposition}

Add Hardner to Composite and pour on desired surface

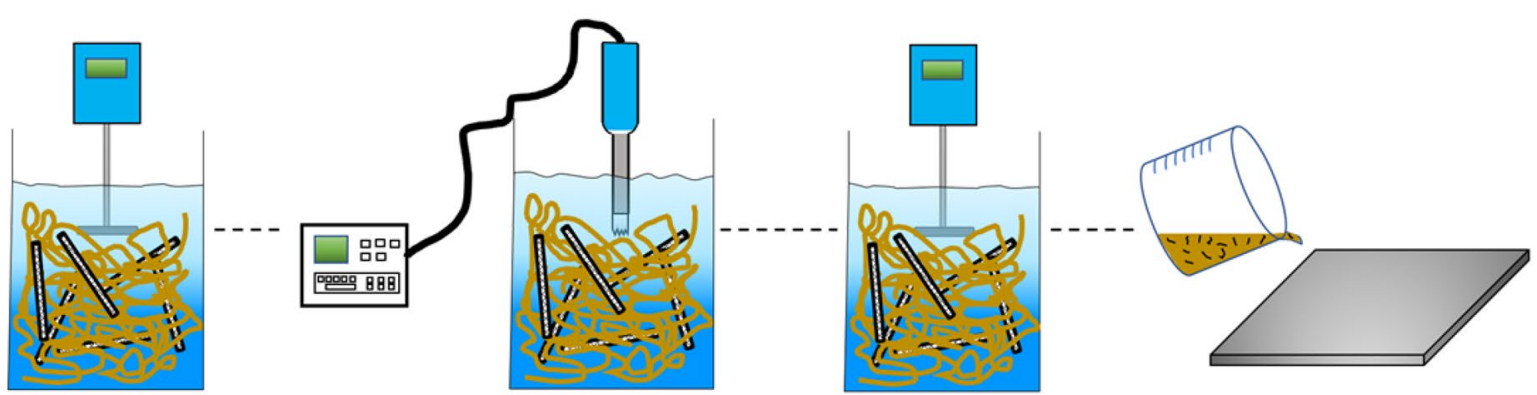

Fig. 1 Process flow chart for the dispersion of MWCNT in the polymer matrix

Mo $<0.01$ wt\%, Ni 0.01 wt \%, Cu 0.02 wt\%, V 0.001 wt\%, Fe $100 \mathrm{wt} \%$ (Spectrolab metal analyzer/OES/fixed). The carbon steel sheet was sandblasted with corundum and then washed with hexane in a sonicator bath for $10 \mathrm{~min}$ at $59 \mathrm{kHz}$ (Falc Instruments LBS2, Treviglio, Bergamo, Italy).

\subsection{Film application and curing}

The liquid suspensions were applied by a spray gun. A layer by layer wet deposition technique was adopted for MWCNT content greater than $20 \%$, with a weak thermal treatment at $80^{\circ} \mathrm{C}$ for 1 min between two successive depositions. The curing step was performed in two stages: $80^{\circ} \mathrm{C}$ for $15 \mathrm{~min}$ and $180^{\circ} \mathrm{C}$ for $15 \mathrm{~min}$. The film thickness was maintained at around $30 \mu \mathrm{m}( \pm 10)$, in order to obtain a complete coating of the surface. At least two specimens were prepared for each formulation.

\subsection{Microscope analysis (SEM, AFM)}

The scanning electron microscope (SEM) used for the surface analysis of the samples was a ZEISS EVO 50 EP spectrometer (Carl Zeiss AG, Oberkochen, Germany). AFM measurements were performed with a NT-MDT Solver pro, in contact mode, with a tip CSG10 (constant force $0.01-0.5 \mathrm{~N} / \mathrm{m}$, single crystal silicon) and scanning frequency of $0.8 \mathrm{~Hz}$ on an area of $20 \times 20 \mu \mathrm{m}^{2}$.

\subsection{Resistivity analysis}

The electrical conductivity was measured using a standard two-probes method ASTM D257 [14], measuring the volume resistivity of the composite coating with a digital calibrated multimeter (Thurlby Thandar Instruments Ltd., Glebe Road, Huntingdon. Cambs. PE29 7DX UK). In order to obtain reliable resistivity data on a larger surface, two copper probes were placed on the surface of the coating film and the resistance of the film was measured after a short stabilisation time. The device was composed by a Teflon support and two square copper rods, interspaced 
by $1 \mathrm{~cm}$, of $1 \mathrm{~cm}^{2}$ section area. A conductive non-ionic gel was used to increase the contact efficiency.

\subsection{Electrochemical measurements}

Electrochemical impedance analyses (EIS) and potentiodynamic tests were performed using an Autolab PGSTAT30 potentiostat/galvanostat equipped with FRA (Frequency Response Analyser) software. A three-electrode cell, consisting in the working electrode, a titanium MMO counter electrode and a calomel reference electrode, was used. These electrodes were immersed in a $\mathrm{NaCl}(5 \% \mathrm{w} / \mathrm{w})$ electrolyte solution. Each sample was placed in the cell and analysed following a specific sequence order. Initially, the open circuit potential (OCP) was evaluated for $1 \mathrm{~h}$, in order to stabilize the system. After this step, the EIS and the linear sweep voltammetry (potentiodynamic analysis), separated by a resting time of $2 \mathrm{~min}$ at OCP, have been measured.

The EIS analysis was carried out by applying an AC potential, while measuring the current. An amplitude of $10 \mathrm{mV}$, a start frequency of $300 \mathrm{kHz}$ and an end frequency of $10 \mathrm{mHz}$ were used.

The potentiodynamic measurements were obtained varying the voltage linearly with time between two values. The scan rate was of $1 \mathrm{mV} / \mathrm{s}$, with a starting value of $-75 \mathrm{mV}$ and an end point of $1 \mathrm{~V}$, with respect to the OCP. Potentiodynamic plots reported the voltage required by the corrosion process versus the corrosion current in logarithmic scale.

\subsubsection{Hardness analysis}

In order to characterize the surface hardness of the composite coatings at different MWCNT concentrations, the Vickers hardness analysis was performed with a WIN-HCU Fisher instrument following the DIN 50359/ISO15577 normative $(\mathrm{F}=5000 \mathrm{mN}$ for $10 \mathrm{~s})$.

\subsubsection{OCA measurement}

Optical contact angles were measured with a OCA 15 plus (Dataphysics Instruments corp., USA) using the static drop method.

\section{Results and discussion}

The filler/polymer ratio is one of the main constraints affecting the properties of a coating. In our case, two quantitative parameters describe the filler-polymer relationship: the critical pigment volume concentration (CPVC) and the electrical percolation threshold (EPT). The CPVC parameter is the threshold of the volume filler-polymer ratio under which the resin completely wets the surface of solid particles. If, on the contrary, the ratio is above this threshold, porosity increases, and mechanical and physical properties change. Our experimental tests set the CPVC in between the 5.5-7.5 wt\% of MWCNT. The EPT, instead, represents the critical concentration value at which a longrange connected network of filler's particles appears, and it is influenced by the distributions of particle diameters and nanotube lengths (aspect ratio). Therefore, EPT is affected by the amount and spread of particles, being both related to the continuity grade of the 3D filler-network. Besides, several other parameters strongly affect the EPT, such as the application method [15]. A range of EPT values from 0.1 to $3.2 \mathrm{wt} \%$ for MWCNT appeared in the literature, while experiments on CNT set the threshold at around $4.5 \mathrm{wt} \%$ [10]. The exact low limit for EPT is reported to depend on the preparation method $[16,17]$.

\subsection{Microscope analysis}

The comparison of SEM images at the same magnification $(1,000 x)$, presented in Fig. 2, evidences the porosity changes at varying the concentration of MWCNTs. At concentration above $6 \mathrm{wt} \%$, carbon nanotubes tend to aggregate and we observe a deep variation of the surface morphology. It appears clear indeed that the smooth areas of the resin gradually disappear, forming thin and discontinuous films that cover the aggregated particles. The particle-aggregate structures, however, seem to remain jammed each other.

The SEM pictures of the samples at $20 \mathrm{wt} \%$ and $50 \mathrm{wt} \%$, magnified at 5,000x, evidence the growing dimension of aggregates and pores (Fig. 3).

Increasing the magnification at 20,000x, the MWCNT aggregates appear linked to each other by well-separated MWCNT filaments (Fig. 4).

\subsection{Surface roughness}

AFM images (Fig. 5) show that a MWCNTs concentration higher than $6 \mathrm{wt} \%$ creates a pronounced roughness. The peak height increases by more than 10 times (from 200 to $2500 \mathrm{~nm}$ ) from the specimen coated with pure epoxy resin to that coated with a MWCNT concentration of $50 \mathrm{wt} \%$.

The plots reported in Fig. 6 show the average roughness $\left(\mathrm{S}_{\mathrm{a}}\right)$ and the skewness $\left(\mathrm{S}_{\mathrm{sk}}\right)$ of the samples. The changes of the $S_{s k}$ values, namely the degree of bias of the roughness shape (asperity), indicate that, at low MWCNT content (0-10 wt\%), the coating surface is characterized by low roughness and by peaks and asperities $\left(S_{s k}>0\right)$, while, at higher concentrations, the average roughness is higher, the number of valleys increases 
Fig. 2 SEM microphotographs $(1000 \times)$ of carbon steel substrates coated with a pure epoxy resin and MWCNTs dispersed in epoxy resin at concentrations of $\mathbf{b} 4 \mathrm{wt} \%$, $\mathbf{c}$ $6 \mathrm{wt} \%$, d 8 wt $\%$, e 20 wt $\%$ and f $50 \mathrm{wt} \%$
Fig. 3 SEM pictures $(5000 \times)$ of carbon steel coated with MWCNTs dispersed in epoxy resin at concentrations of a $20 \mathrm{wt} \%$ and $\mathbf{b} 50$ wt $\%$ a
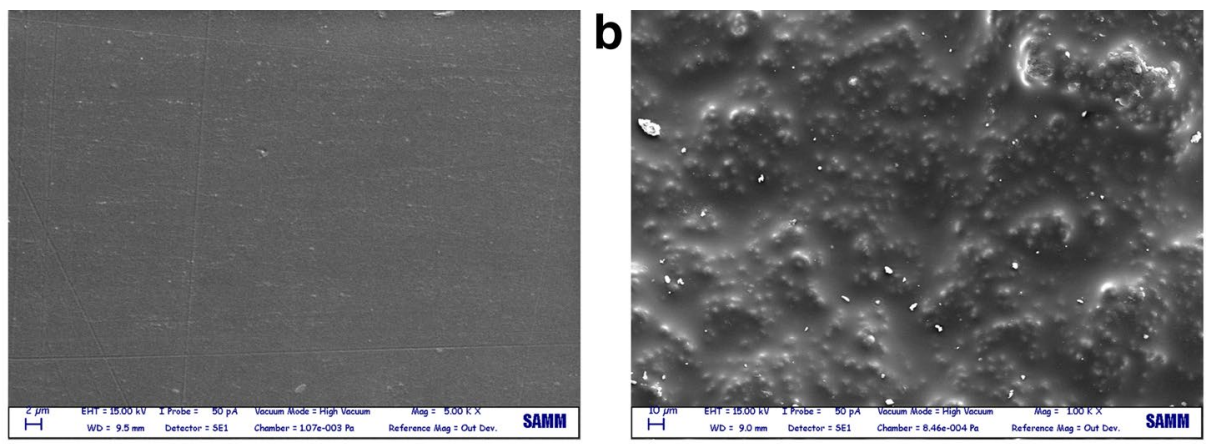

C

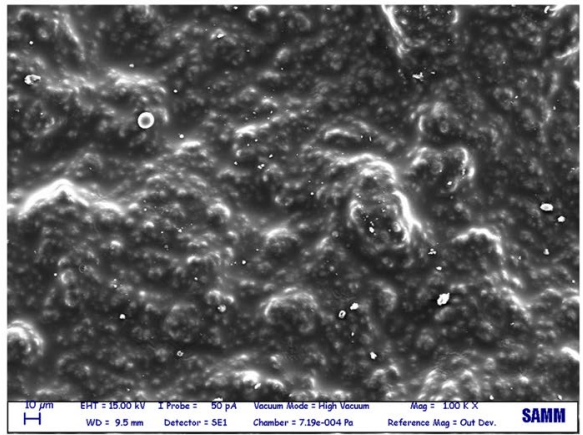

e
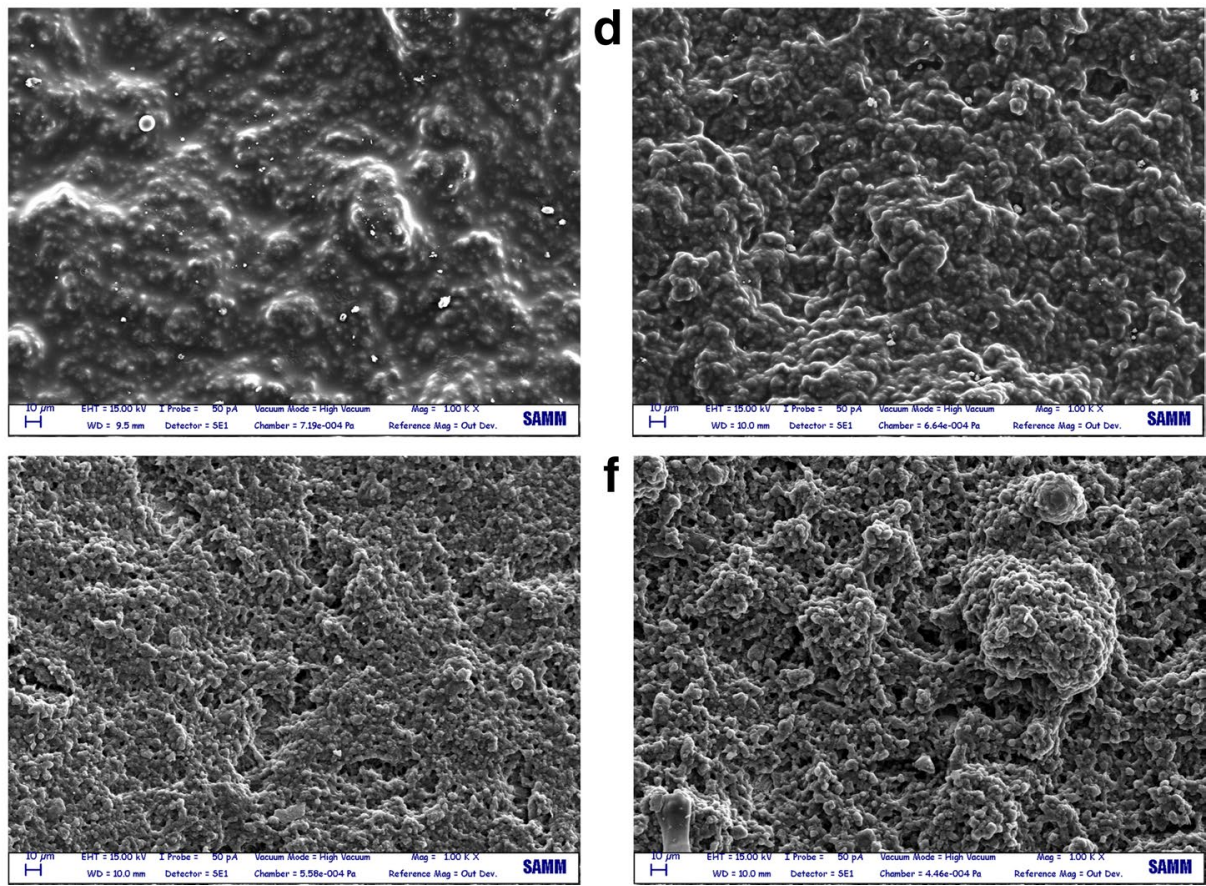

f

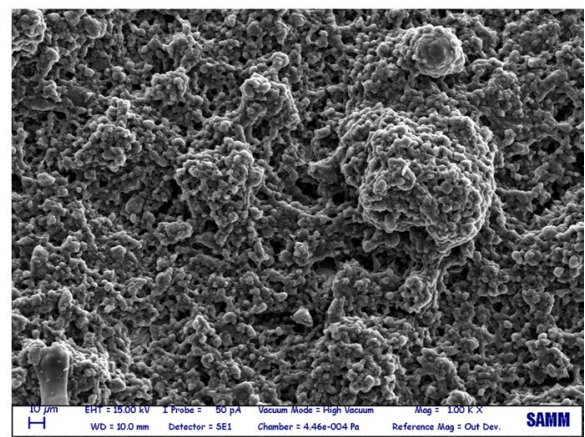

a

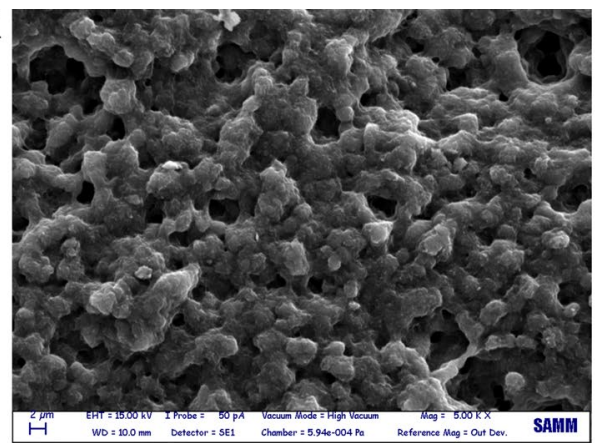

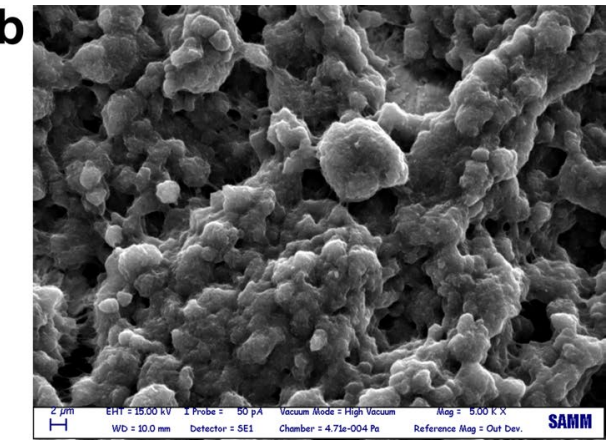

and height distribution (peaks and valleys) is symmetrical around the mean plane $\left(\mathrm{S}_{\mathrm{sk}} \approx 0\right)$.

The average roughness $\left(S_{a}\right)$, the root mean square roughness $\left(S_{q}\right)$ and the maximum peaks height $\left(R_{\max }\right)$ of the MWCNT coatings at different concentrations are shown in Table 1.

\subsection{Mechanical properties}

The Vickers hardness of the coatings was investigated by carrying out indentation tests with a load of $5 \mathrm{mN}(10 \mathrm{~s})$. Several indentations were made over the single specimen surface and the average value was taken (Fig. 7).

The results put in evidence a significant hardness increase of the composite film at MWCNT concentrations 


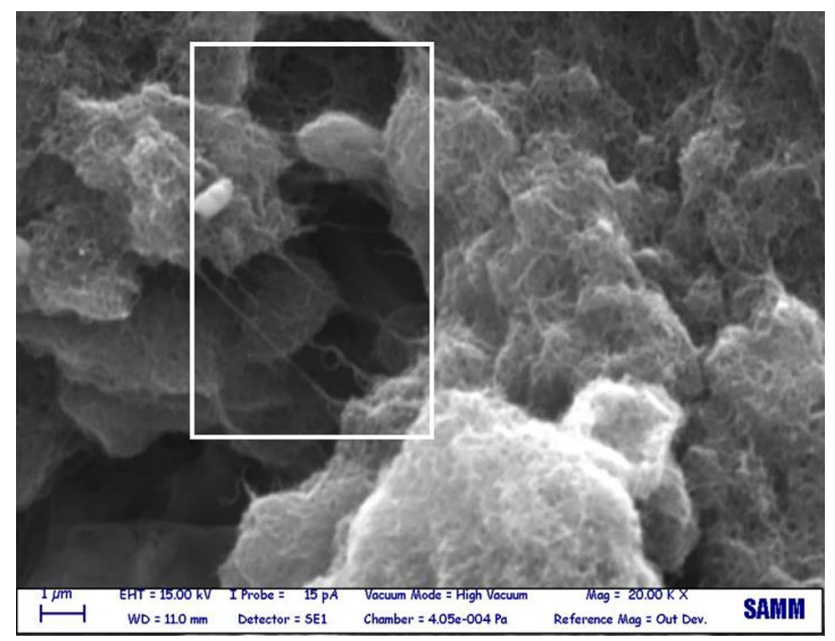

Fig. 4 SEM pictures $(20,000 \times)$ of carbon steel coated with MWCNTs dispersed in epoxy resin at a concentration of $50 \mathrm{wt} \%$. The box enlightens the fibrous bonds among the aggregates

around $4 \mathrm{wt} \%$ compared to the pure epoxy resin, indicating that the addition of carbon nanotubes positively affects the hardness up to $4 \mathrm{wt} \%$. The results agree with the literature [18]. At higher values ( $>4 \%)$ the hardness decreases, reaching values close to zero at $50 \%$ of MWCNT probably due to the air entrapped in the coating when the particle content is over the CPVC limit.

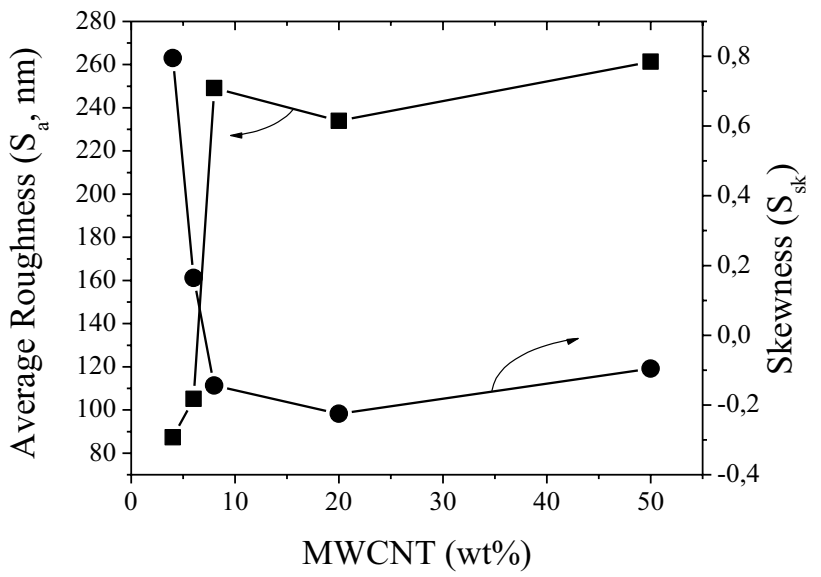

Fig. 6 Average roughness (black square) and skewness (void circle) values of carbon steel coated with epoxy resin at different MWCNT content

\subsection{Surface tension}

The water contact angles (WCAs) increase significantly in the $10-20 w t \%$ range of MWCNTs content (Fig. 8). Outside this interval, a smooth change in the WCA values and a slight slope decrease was detected. The shape of the curve let us to suppose that while the contribution of the polymer is permanent also at higher roughness values, the

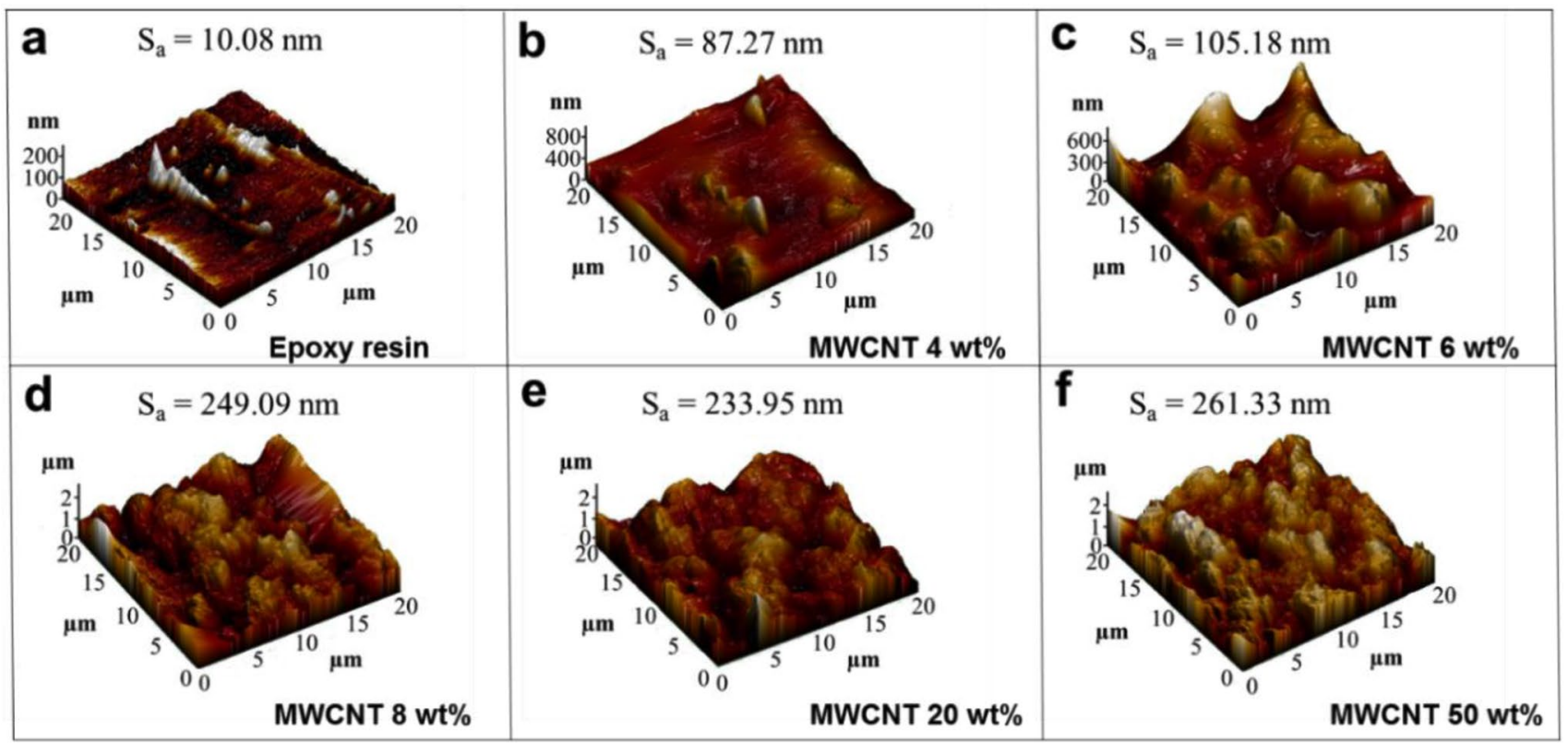

Fig. 5 AFM pictures of carbon steel coated with a pure epoxy resin and MWCNTs dispersed in epoxy resin at concentrations of b 4 wt\%, $\mathbf{c}$ $6 \mathrm{wt} \%$, d $8 \mathrm{wt} \%$, e $20 \mathrm{wt} \%$ and $\mathbf{f} 50 \mathrm{wt} \%$

\section{SN Applied Sciences}


Table 1 Amplitude parameters from AFM analyses

\begin{tabular}{lccc}
\hline & $\mathrm{S}_{\mathrm{a}}(\mathrm{nm})$ & $\mathrm{S}_{\mathrm{q}}(\mathrm{nm})$ & $\mathrm{R}_{\max }(\mathrm{nm})$ \\
\hline Epoxy resin & 10.1 & 15.1 & 227.3 \\
CNT 4\% & 87.3 & 121.4 & 1111.5 \\
CNT 6\% & 105.2 & 131.1 & 885.3 \\
CNT 8\% & 249.1 & 307.8 & 2178.6 \\
CNT 20\% & 233.9 & 291.9 & 2415.1 \\
CNT 50\% & 261.3 & 327.9 & 2276.8 \\
\hline
\end{tabular}

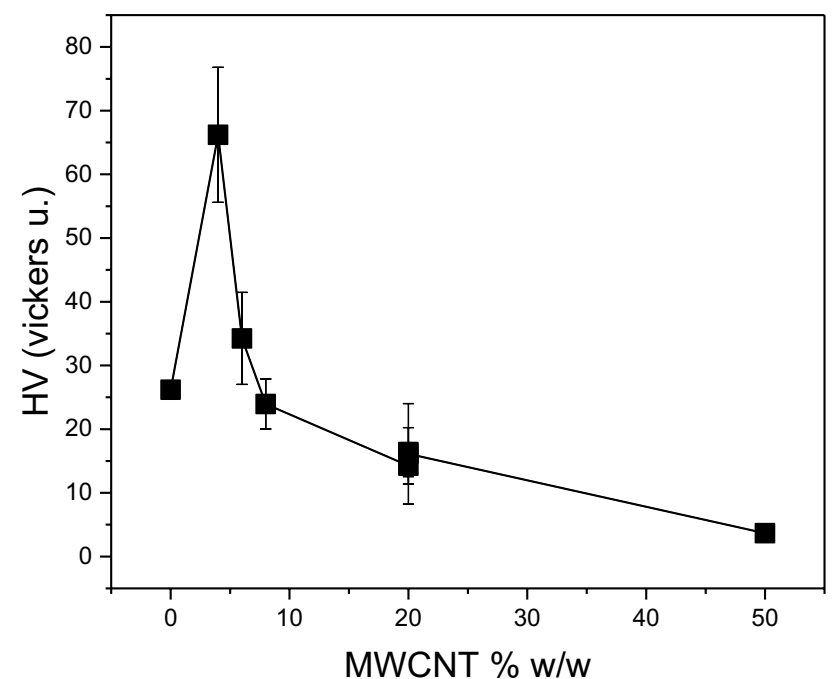

Fig. 7 Vickers hardness values of carbon steel coated with epoxy resin at different MWCNTs concentrations. The standard deviation at 0 and 50 MWCNT \% w/w is lower than 0.5

morphological aspect, like the skewness, is the dominant surface parameter for surface tension.

\subsection{Conductivity}

Resistivity values at different MWCNT concentrations are presented in Fig. 9. An increase of one order of magnitude in the conductivity is observed in the interval 4-10 wt\%, in agreement with the results reported in literature, that place the greatest conductivity around the EPT. At higher MWCNT concentrations the resistivity further decreases, although with a lower slope. This behaviour could be unexpected, considering that at higher filler concentrations the porosity increases. Nevertheless, the resistivity data let us conclude that enriching the network of carbon particles over the CPVC increases the MWCNT composite's conductivity, despite the high number of voids in the coating. The shape of the resistivity curve seems to suggest, in agreement with the SEM observations, that the electrical links are not totally interrupted, and the agglomerates are

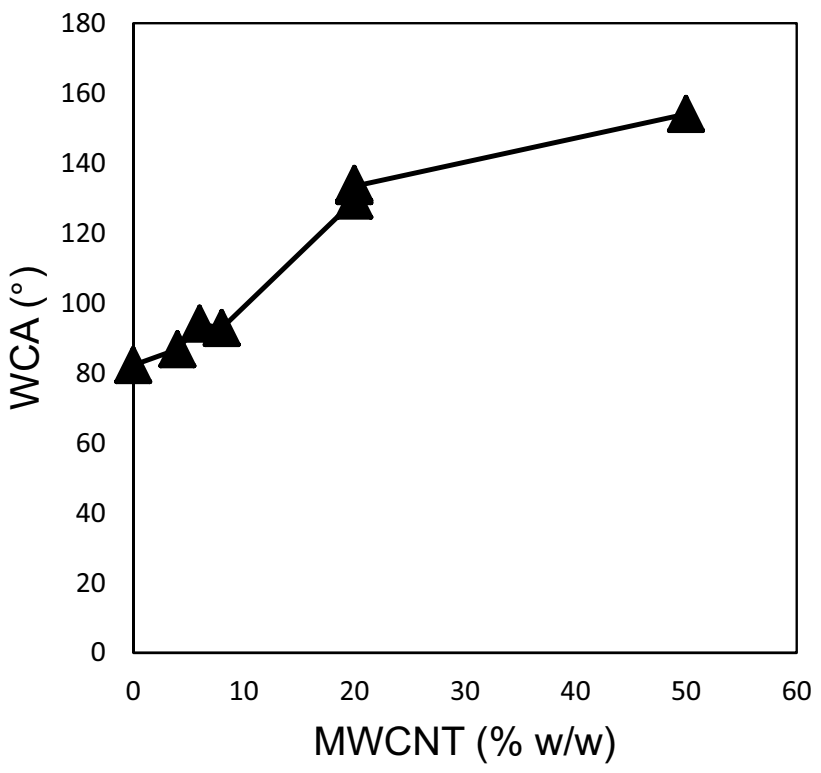

Fig. 8 Water contact angles (WCAs) values of carbon steel coated with epoxy resin at different MWCNTs concentrations

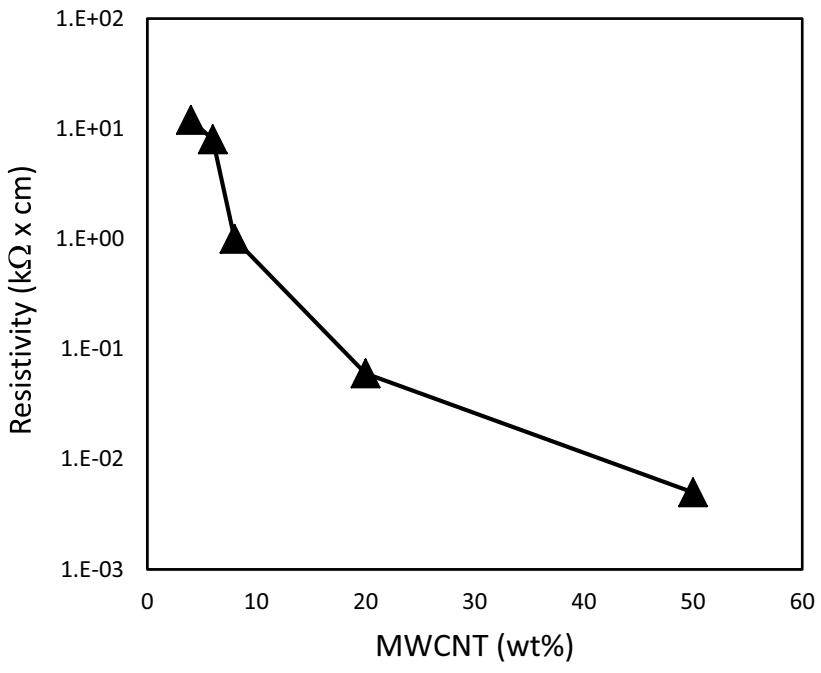

Fig. 9 Resistivity values of carbon steel coated with epoxy resin at different MWCNTs concentrations

bound to each other. However, in MWCNT composite coatings, a long and complex procedure is needed, and a network has to be realized to produce nanotube sequences for electrical conductance.

\subsection{EIS and potentiodynamic tests}

Figure 10a shows the EIS curves of the samples coated with MWCNTs concentrations of $6-8 \mathrm{wt} \%$, while Fig. $10 \mathrm{~b}$ reports those for the highest concentrations ( $\geq 20 \mathrm{wt} \%$ ). Considering that an increase in the $z^{\prime}$ values (the real impedance 

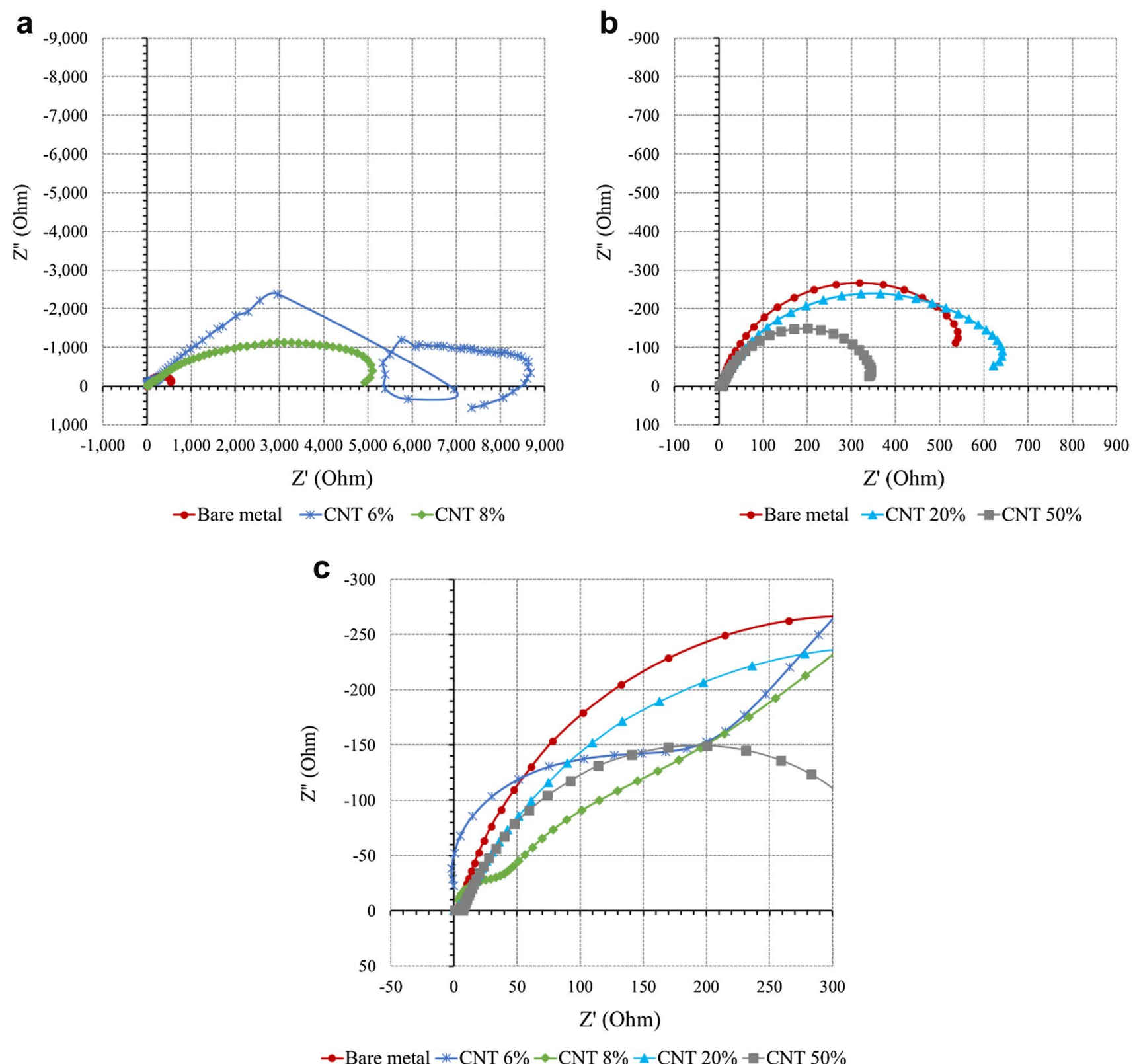

Fig. 10 EIS Nyquist plot of carbon steel coated with epoxy resin at different MWCNTs concentrations compared to bare metal: a 6-8 wt\%, b 20-50 wt\% and c comparison at high frequencies

component) indicates an increased corrosion resistance, the curves related to a MWCNT concentration of $68 \mathrm{wt} \%$ present significant, nonetheless low, trend variation: $z^{\prime}$ data for both samples are greater than those of bare metal. Moreover, the $z^{\prime}$ values of the sample with a MWCNTs amount of $6 \mathrm{wt} \%$ seem to be higher than those obtained with a concentration of $8 \mathrm{wt} \%$. However, at $6 \mathrm{wt} \%$ a double curve is observed, probably meaning the existence of two (or more) types of coating. The samples with high MWCNT percentages present comparable trends, similar to that of the pure metal. However, a corrosion protection behaviour of the coatings at low concentrations is assessed. Indeed, appreciable differences are observed for the impedance values at MWCNT amounts higher than $20 \mathrm{wt} \%$, where the $z^{\prime}$ values are one order of magnitude lower, due to a significant difference in the material responses related to corrosion behaviour.

The results of the potentiodynamic tests confirm the observations argued before (Fig. 11). The $4 \mathrm{wt} \%, 6 \mathrm{wt} \%$, $8 \mathrm{wt} \%$ specimens (Fig. 11a) have a significant reduction of the corrosion currents and an increase of the potential values. Concentrations of MWCNTs higher than $20 \mathrm{wt} \%$ 

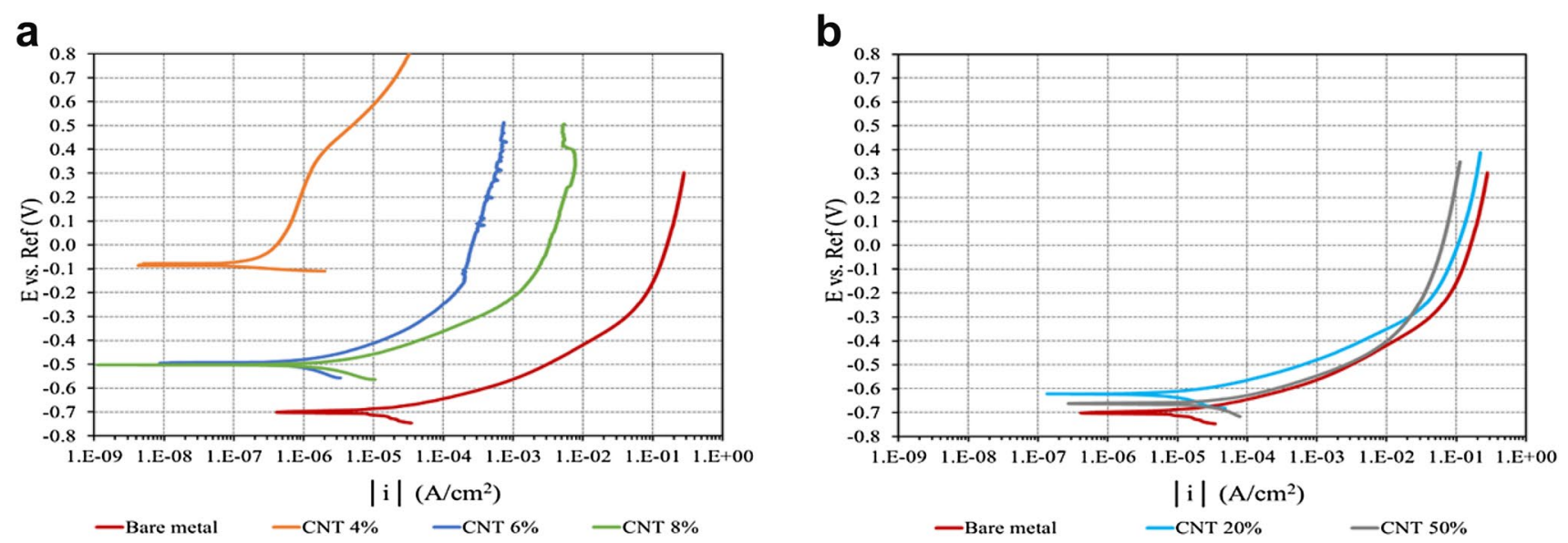

Fig. 11 Potentiodynamic plots of carbon steel coated with epoxy resin at different MWCNTs concentrations compared to bare metal: a 4-6-8 wt\% and b 20-50 wt\%

Table 2 Tafel parameters of potentiodynamic tests on bare metal and MWCNTs composite coatings

\begin{tabular}{lllllr}
\hline & $\begin{array}{l}\mathrm{i}_{\text {corr }} \\
\left(\mathrm{A} / \mathrm{cm}^{2}\right)\end{array}$ & $\begin{array}{l}\mathrm{E}_{\text {corr }} \\
(\mathrm{V})\end{array}$ & $\begin{array}{l}\beta_{\mathrm{a}} \\
(\mathrm{V} / \mathrm{dec})\end{array}$ & $\begin{array}{l}-\beta_{\mathrm{c}} \\
(\mathrm{V} / \mathrm{dec})\end{array}$ & $\begin{array}{l}\mathrm{R}_{\mathrm{p}} \\
\left(\Omega \mathrm{cm}^{2}\right)\end{array}$ \\
\hline Bare metal & $1.08 \mathrm{E}-05$ & -0.71 & 0.067 & 0.080 & $\begin{array}{r}637.17 \\
\text { CNT 4\% }\end{array}$ \\
$3.17 \mathrm{E}-07$ & -0.10 & 0.643 & 0.018 & $153,581.00$ \\
CNT 6\% & $1.11 \mathrm{E}-06$ & -0.51 & 0.108 & 0.107 & $14,009.00$ \\
CNT 8\% & $2.12 \mathrm{E}-06$ & -0.51 & 0.080 & 0.089 & 5050.00 \\
CNT 20\% & $1.25 \mathrm{E}-05$ & -0.64 & 0.079 & 0.107 & 952.30 \\
CNT 50\% & $3.54 \mathrm{E}-05$ & -0.67 & 0.089 & 0.116 & 320.03 \\
\hline
\end{tabular}

(Fig. 11b) cause similar potentiodynamic trends and comparable to that of the pure metal. The reduction of corrosion currents, however, appears not to be enough to assess that the coatings have a pronounced anticorrosive property.

Table 2 shows the Tafel parameters ( $\mathrm{i}_{\text {corr }} \mathrm{E}_{\text {corr }}$ Tafel slopes $\beta_{a}$ and $\beta_{c}$, and polarization resistance $R_{p}$ ) of the potentiodynamic tests carried out on bare metal and carbon steel coated with different concentrations of MWCNTs. Generally, $\mathrm{i}_{\text {corr }}$ increased with the concentration of MWCNTs, with values at $20-50 \%$ similar to that achieved for the bare metal. On the other hand, polarization resistance decreased when the MWCNTs concentration was higher.

\section{Conclusions}

Conductivity and physico-mechanical properties of MWCNT-epoxy coatings have been evaluated, up to a MWCNT concentration of $50 \%$, considering the two parameters related to the filler/polymer ratio: the critical pigment volume concentration (CPVC) and the electrical percolation limit (EPT). The former highlights that at MWCNT content higher than $6-7 \%$ the wetting at the particle-polymer interface becomes discontinuous; the second, EPT, seems to have a very low value $(\leq 4 \%)$, as evidenced by the decrease of the electrical resistivity by increasing the MWCNT load.

Other properties have been related to the filler/polymer ratio. The hardness had a maximum peak at a MWCNT concentration of $6 \mathrm{wt} \%$ and dramatically fell down at higher loads. On the other side, the uniform skewness, referred to peaks and valleys, was associated to the homogeneity degree of dispersion and to the arrangement of MWCNTs.

The electrical conductivity did not significantly suffer the coating porosity as one would have expected, but it increased with the MWCNT concentration. This behaviour could be due to the MWCNT bridges among the agglomerates, as evidenced by the SEM microphotographs: the electrical continuity was ensured as the MWCNTs became more densely packed and by the MWCNT wires stretched configuration. The drawbacks of the increased content of the filler are the diminished mechanical properties, as expected when the solid content is above the CPVC. The comparability of the results for mechanical or electrical properties with other studies is however restricted due to different carbon materials and surface functionalization, deviating production processes (dispersion and nanotube stabilization) and different polymer properties.

It is worth to note that the goal of building carbon composite coatings with anticorrosion properties might be obtained at concentrations higher than the CPVC, as high WCA is observed at high MWCNT contents, when the obtained surfaces have a low skewness. The future activity of the research could take into account the durability performance in test conditions. 
Acknowledgements This work was sponsored by the FP7 People: Marie-Curie Actions.

Funding This research has received funding from the Project SLUDGEtreat, co-funded by the European Commission within the FP7 (2007-2013) Marie Curie Actions - Industry-Academia Partnerships and Pathways - IAPP, GA n. 611593.

\section{Compliance with ethical standards}

Conflict of interest The authors declare that they have no conflict of interest.

Human and animal rights The research did not involve human participants and/or animals.

\section{References}

1. Mahmoud A, Olivier J, Vaxelaire J, Hoadley AFA (2010) Electrical field: a historical review of its application and contributions in wastewater sludge dewatering. Water Res 44:2381-2407. https ://doi.org/10.1016/j.watres.2010.01.033

2. Visigalli S, Turolla A, Gronchi P, Canziani R (2017) Performance of electro-osmotic dewatering on different types of sewage sludge. Environ Res 157:30-36. https://doi.org/10.1016/j.envre s.2017.05.015

3. Gronchi $P$, Canziani R, Brenna A, Visigalli S, Colominas C, Montalà F, Cot V, Stradi A, Ferrari G, Diaz C, Fuentes GG, Georgiadis A (2017) Electrode surface treatments in sludge electro-osmosis dewatering. Mater Manuf Process 32:1265-1273. https://doi. org/10.1080/10426914.2017.1279313

4. Zhang Y, Cao M, Lv H, Wei J, Gu Y, Liu D, Zhang W, Ryan MP, Wu $X$ (2018) Electrodeposited nanometer-size IrO2/Ti electrodes with $0.3 \mathrm{mg}$ IrO2 $\mathrm{cm}-2$ for sludge dewatering electrolysers. Electrochim Acta 265:507-513. https://doi.org/10.1016/j.elect acta.2018.01.190

5. Zhang S, Yang Z, Lv X, Zhi S, Wang Y, Li Q, Zhang K (2017) Novel electro-dewatering system for activated sludge biosolids in bench-scale, pilot-scale and industrial-scale applications. Chem Eng Res Des 121:44-56. https://doi.org/10.1016/j.cherd .2017 .02 .035

6. Savarino $L(X X X X)$ Epoxy-CNTs composite coatings for conductive and anticorrosive applications. Master thesis, Politecnico di Milano, AA 16/17
7. Yedra Á, Gutiérrez-Somavilla G, Manteca-Martínez C, GonzálezBarriuso M, Soriano L (2016) Conductive paints development through nanotechnology. Progr Org Coat 95:85-90. https://doi. org/10.1016/j.porgcoat.2016.03.001

8. Schilde C, Schlomann M, Overbeck A, Linke S, Kwad A (2015) Thermal, mechanical and electrical properties of highly loaded CNT epoxy composites A model for the electric conductivity. Compos Sci Technol 117:183-190. https://doi.org/10.1016/j. compscitech.2015.06.013

9. Mohammadi S, Taromi FA, Shariatpanahi H, Neshati J, Hemmati $M$ (2014) Electrochemical and anticorrosion behaviour of functionalized graphite nanoplatelets epoxy coating. J Ind Eng Chem 20:4124-4139. https://doi.org/10.1016/j.jiec.2014.01.011

10. Zeng X, Xu X, Shenai PM, Kovalev E, Baudot C, Mathews N, Zhao $Y$ (2011) Characteristics of the electrical percolation in carbon nanotubes/polymer nanocomposites. J Phys Chem C 115:21685-21690. https://doi.org/10.1021/jp207388n

11. Sandler JKW, Kirk JE, Kinloch IA, Shaffer MSP, Windle AH (2003) Ultra-low electrical percolation threshold in carbon-nanotubeepoxy. Polymer 44:5893-5899. https://doi.org/10.1016/S0032 -3861(03)00539-1

12. Bauhofer W, Kovacs JZ (2009) A review and analysis of electrical percolation in carbon nanotube polymer composites. Compos Sci Technol 69:1486-1498

13. Chakraborty AK, Plyhm T, Barbezat M, Necola A, Terrasi GP (2011) Carbon nanotube (CNT)-epoxy nanocomposites: a systematic investigation of CNT dispersion. J Nanopart Res 13:6493-6506. https://doi.org/10.1007/s11051-011-0552-3

14. ASTM D257-14 Standard Test Methods for DC Resistance or Conductance of Insulating Materials

15. Kovacs JZ, Bauhofer W (2009) The influence of the dispersion quality of carbon nanotubes in an epoxy matrix on the electrical conductivity of the composite. In: Proceedings ICCM-17, Edinburgh, Scotland July 27-31. p E1.32

16. Kovacs JZ, Velagala BS, Schulte K, Bauhofer W (2007) Two percolation thresholds in carbon nanotube epoxy composites. Compos Sci Technol 67:922-928

17. Li J, Ma PC, Chow WS, To CK, Tang BZ, Kim JK (2007) Correlations between percolation threshold, dispersion state, and aspect ratio of carbon nanotubes. Adv Funct Mater 17:3207-3215

18. Coleman JN, Khan U, Gk YG (2006) Mechanical reinforcement of polymers using carbon nanotubes. Adv Mater 18:689-706

Publisher's Note Springer Nature remains neutral with regard to jurisdictional claims in published maps and institutional affiliations. 